\title{
THE IMPACT OF INTERACTIVE CORPORATE SOCIAL RESPONSIBILITY COMMUNICATION ON CORPORATE REPUTATION
}

\begin{abstract}
Companies increasingly communicate about corporate social responsibility (CSR) through interactive online media. We examine whether using such media is beneficial to a company's reputation. We conducted an online experiment to examine the impacts of interactivity in CSR communication on corporate reputation and word-of-mouth intentions. Our findings suggest that an increase in perceived interactivity leads to higher message credibility and stronger feelings of identification with the company, which also boost corporate reputation and word-of-mouth. This result implies that using interactive channels to communicate about CSR can improve corporate reputation. Our results also show that the detrimental impacts of negative user evaluations on corporate reputation are much higher than the favorable impacts of positive evaluations. This finding suggests that, despite the effectiveness of interactive communication channels, firms need to carefully monitor these channels.
\end{abstract}

Keywords: Corporate reputation, corporate social responsibility, electronic word-of-mouth, interactivity, message credibility, social media. 


\section{Introduction}

Companies are increasingly communicating about their efforts in the realm of corporate social responsibility (CSR), that is, efforts to "integrate social, environmental, ethical, human rights and consumer issues into their business operations and core strategy” (European Commission 2011 p. 6). A major goal of such communication is to achieve or protect organizational legitimacy (Arvidsson, 2010). Furthermore, companies are embracing interactive online media to communicate about CSR. For example, Kim et al. (2010) showed that 71\% of the Fortune Global 500 firms devoted a separate section of their website to environmental responsibility and $75 \%$ of these environmental sections gave users the opportunity to respond to the information provided. It is unclear, however, whether using such interactive media adds value to corporate communication strategies regarding CSR. Companies are increasingly concerned about the impact of the use of interactive communication on their reputations. For example, in March 2010, Greenpeace attacked Nestlé about its palm oil suppliers whose practices endangered the orangutan. Its YouTube movie “Have a Break?” (YouTube 2010), which shows an employee chewing an orangutan's finger in the shape of a Kit-Kat, has been watched $1.5 \mathrm{~m}$ times and has caused 200,000 protest emails. After trying to bury the nasty spoof, Nestlé suspended all orders from the accused supplier (The Economist 2010). Greenpeace’s video caused a virtual boycott campaign against Nestlé and overwhelmed the company’s Facebook page with negative comments (e.g., McCarthy, 2010). Unable to stop the video from spreading around the globe, it is in the company's interest to understand the impact of such communication on its reputation.

Several studies have examined the effectiveness of communication about CSR toward consumers and other stakeholders, in terms of its effects on attitudes and loyalty (see Du et al. 
2010, for a review). They have generally concluded that overall, CSR communication has a positive effect on stakeholder attitudes and behaviors (e.g., Sen et al. 2006). However, the independence of the source through which CSR is communicated (company-controlled versus third party-controlled) influences the credibility of the communication, and hence its effectiveness in terms of changing stakeholder attitudes and behavior. Other factors that influence the credibility and effectiveness of communication include the professed motives of a company to engage in CSR (e.g., Forehand and Grier 2003), and the degree to which the CSR activities are a logical fit with the company's core business (e.g., Simmons and Becker-Olsen 2006).

Furthermore, studies on online media have shown that the interactivity of these media has a positive effect on attitudes towards companies and brands (e.g., Van Noort et al., 2012). Little is known about how interactive online media change the effect of corporate communication about CSR. Du et al. (2010) argue that the use of interactive media is likely to increase the effectiveness of corporate communication about CSR, because users can easily spread the communication messages to others. In contrast, Fieseler et al.’s (2010) study of McDonald's CSR blog suggests that messages on the blog have minimal influence beyond a select group of dedicated followers. Neither of these studies, however, discusses the effect of interactive media on the credibility and appeal of CSR messages. For example, when a company communicates about CSR through interactive media, the distinction between company-controlled and third party-controlled media becomes blurred because stakeholders' opinions are directly included in the communication (provided that other users are able to see their responses). This phenomenon might have implications for the credibility of CSR messages, ultimately influencing their effectiveness in terms of stakeholder attitudes and behavior. 
This paper investigates whether allowing stakeholders to post comments on CSR messages (and to read comments posted by others) affects the credibility of messages and stakeholders' feeling of identification with the company. Furthermore, we examine the effects of improved message credibility and identification on the reputation of the company and positive word-ofmouth intentions. We also analyze the effects of user evaluations, testing the conventional wisdom that messages having mostly positive comments have a higher credibility than messages having no user comments, while the reverse holds for messages having mostly negative comments. Our findings suggest that an increase in perceived (but not actual) interactivity leads to higher message credibility and stronger feelings of identification with the company, which also boost corporate reputation and word-of-mouth. This result implies that using more interactive channels to communicate CSR could improve corporate reputation. Our results also show that the detrimental impacts of negative comments on corporate reputation are much higher than the favorable impacts of positive comments, consistent with the phenomenon of a negativity bias (e.g., Rozin and Royzman 2001). This finding suggests that, despite the effectiveness of interactive communication channels, firms need to carefully monitor these channels.

This paper makes two original contributions to the literature and to business practices. First, past research has not clearly identified the relationship between interactivity and corporate reputation. Previous studies have found positive effects of two-way communication and other dimensions of interactivity on attitudes toward companies and brands (e.g., McMillan and Hwang 2002; Van Noort et al. 2012). They have found these effects to be mediated by constructs like arousal and pleasure (Fiore et al. 2005), comprehension of the communication's content (Macias 2003) and flow (Van Noort et al. 2012). However, these studies have mainly looked at product brands and product attributes. We believe that our paper contributes to the literature by 
investigating the effects of interactive communication on company-related attributes, i.e., CSR. These are different from product attributes because they are often related to societal issues that are likely to generate discussion and debate. In addition, research by Sen and Lerman (2007) suggests that negative product reviews have more effect than positive reviews, but only for utilitarian products rather than hedonic ones. CSR generally seems more similar to utilitarian products than to hedonic ones. Although there is a 'feel-good' factor in CSR, the performance of a company in terms of its social or environmental impact is usually something objective and concrete, rather than something that is experienced subjectively by individual stakeholders. Therefore, based on Sen and Lerman's (2003) results we would expect negative comments about CSR to have more impact than positive comments, while this may not hold for products with hedonic attributes. Indeed, several studies have demonstrated a negativity effect with respect to CSR communication (e.g., Folkes and Kamins 1999).

Second, this paper is of particular importance to management and public relations decisionmaking. Many firms are currently experimenting with various online corporate communication and social media channels. This study explains to what extent the use of interaction in CSR messages increases their effectiveness in terms of word-of-mouth and ultimately corporate reputation.

\section{Conceptual Model and Hypothesis Development}

The central assertion of this paper is that the use of interaction in a company's communication about CSR positively influences corporate reputation as well as word-of-mouth behavior. In addition, the valence of other stakeholders' comments positively influences reputation and word-of-mouth. We also suggest that credibility of the company's communication 
and identification with the company mediate the influence of interactivity and the valence of comments on the reputation of the company and on word-of-mouth intentions. The conceptual model is presented in Figure 1.

INSERT FIGURE 1 HERE

Following McMillan (2006, p. 168), we define interactivity as "two-way communication between source and receiver”. Using McMillan’s (2006) framework of online interactivity, we focus on user-to-user (in this case, user-to-company) interaction (rather than user-to-system or user-to-document interaction),. Using the framework of Grunig and Hunt (1984), we examine the effects of two-way communication compared to one-way communication. We do not investigate the effects of symmetric versus asymmetric communication, i.e., whether the company actually uses the comments it receives to change its policies (symmetric) or only to monitor stakeholder sentiments (asymmetric). Furthermore, we focus on a setting in which users typically comment on a central message, but not frequently on other comments, and even less frequently on comments on comments. Such a setting is characteristic of channels like YouTube, and can be called "reactive" as opposed to truly "interactive" (Walther et al. 2010).

Impact of Communication Interactivity on Message Credibility

We first suggest that interactive corporate communication messages about CSR have a higher credibility than marketer-generated information about CSR. Credibility can be defined as the degree to which a receiver perceives a message to be "truthful and believable” (MacKenzie and Lutz 1989, p. 51). Allowing stakeholders to publish criticism on a company’s CSR messages would presumably quickly expose incorrect or fraudulent claims. Therefore, information about CSR published through interactive online channels is more credible than purely company- 
controlled messages. Furthermore, the fact that the company opens its messages to criticism creates an impression of sincerity (Van Halderen et al. 2011), which also increases message credibility.

In a study using lowly and highly interactive versions of a political candidate’s website, Thorson and Rodgers (2006) found that websites with a high level of perceived interactivity lead to a more positive attitude towards the website, impressions of the candidate, and voting intentions. Thorson and Rodgers (2006) also showed that the degree to which users felt they could trust the information they received, which is closely related to message credibility, is a major mediating factor between perceived interactivity and attitude. These findings suggest that interactive corporate communication messages are perceived as more credible than noninteractive messages. Thus, we propose the following:

Hypothesis 1a: Interactive CSR messages have a higher credibility than non-interactive CSR messages.

Impact of Interactive Communication on Identification

In addition to message credibility, the use of an interactive channel also enhances stakeholder feelings of identification with the company. People actively choose organizations they can identify with, even if they are not formal members (Bhattacharya and Sen, 2003). Identification with an organization can be defined as a process in which a person's beliefs about a relevant organization “become self-referential or self-defining” (Bhattacharya and Sen 2003, p. 77). When a company uses interactive CSR communication, stakeholders are likely to feel more embedded in the social network that the company embodies, because they have a chance to engage in a dialogue with the company and its stakeholders (McMillan 2006). This feeling of embeddedness, in turn, is likely to increase their identification with the company (Bhattacharya 
and Sen 2003). Thorson and Rodgers (2006) empirically confirmed that the ability to interact fosters the creation of an intimate relationship between organization and customers, which can in turn stimulate identification. We hypothesize:

Hypothesis 1b: Interactive CSR messages create higher identification with the company than non-interactive CSR messages.

\section{Impact of User Evaluations on Message Credibility}

Social media channels typically display not only the original message written by the author of the page but also comments by various visitors. Such opinions can be very critical about the statement made on that particular page and sometimes also include ratings. Generally, not all user comments are positive and some executives question whether allowing the public to read previous criticism could harm the corporate brand. For example, in 2007 a publisher of a local newspaper in the United States removed the option to comment on articles, stating that negative comments put the credibility of his paper at risk (Post 2007), only to restore the possibility to comment a few years later.

Prior academic studies also found mixed results concerning the impact of negative reviews on brands and sales. Liu (2006) found that while the volume of word-of-mouth significantly increases box office revenues, there is no considerable difference between positive or negative reviews. The author showed that while consumer awareness is determined by the volume of word-of-mouth, the valence of word-of-mouth (i.e., whether a review is positive or negative) does not have a significant impact on consumer attitudes. Duan et al. (2008) reached a similar conclusion and suggested that online reviews increase consumer awareness instead of directly influencing public opinion. They found that the rating of reviews has no persuasive effect on consumer purchase decisions (Duan et al. 2008). Basuroy et al. (2003), however, showed that 
during the first week of a film's run, negative publicity hurt sales more than positive reviews increase revenues. They attributed this to the existence of influencers, persons having expertise or knowledge on a particular subject.

As Bickart and Schindler (2001) argue, information from other users is generally seen as more credible than information delivered only through the company. If comments by other users are predominantly positive, they should therefore enhance the credibility of the message. On the other hand, mostly negative user comments should decrease message credibility. Indeed, Smith and Vogt (1995) found a link between word-of-mouth and the perceived credibility of advertisement. It seems quite obvious that CSR messages having largely positive user comments are more credible, while messages having largely negative comments are less credible. Less obvious is whether having mixed negative and positive comments is superior to no comments at all. On the one hand, research in social psychology has often demonstrated that negative information has a stronger impact on people's attitudes and impressions than positive information (see Skowronksi and Carlston 1989; Rozin and Royzman 2001). One reason for this phenomenon seems to be that negative information is more diagnostic about an entity than positive information, especially in the domain of morals (Skowronski and Carlston 1989); another reason could be the tendency to strive for perfection, giving a greater weight to deviations from perfection (Rozin and Royzman 2001). If this is indeed the case, we would expect negative information to dominate a setting with mixed comments, leading to a decrease in credibility compared to a situation with no comments. However, this so-called 'negativity effect' does not seem to hold for word-of-mouth. For example, East et al. (2008) found that positive word-of-mouth has a stronger impact on brand purchase probability than negative publicity. Similarly, Doh and Hwang (2009) found that the credibility of electronic word-of-mouth was the 
highest when there were also some negative comments about a product. Presumably, the reason is that when a communication message provokes almost only positive user reactions, consumers may suspect that the company has been manipulating these comments, e.g., through 'stealth marketing' or by deleting overly critical comments. Similarly, when there is no user comment, consumers might also suspect that the company has removing critical comments, or that the message is not relevant enough to respond to. Therefore, we hypothesize:

Hypothesis 2a: CSR messages having mostly positive user evaluations have a higher credibility than CSR messages having a comparable number of positive and negative user evaluations; CSR messages having a comparable number of positive and negative user evaluations have a higher credibility than CSR messages having no user evaluations; and CSR messages having no user evaluations have a higher credibility than CSR messages having mostly negative user evaluations.

\section{Impact of User Evaluations on Identification}

Similarly, we expect the user evaluations to have a positive effect on stakeholder feelings of identification. Bhattacharya and Sen (2003) argue that stakeholders are more likely to identify with organizations whose identities they find attractive. Therefore, a corporate communication message which attracts predominantly negative user evaluations might harm stakeholders' feelings of identification. On the other hand, when there is a similar number of negative and positive user evaluations, stakeholders might identify more strongly with the company than when there are no comments. Stakeholders might be suspicious that the company has been manipulating the discussion when there are no user comments, leading to a less attractive identity and hence less identification. Therefore, we hypothesize:

Hypothesis 2b: CSR messages having mostly positive user evaluations lead to a higher 
identification with the company than CSR messages having a comparable number of positive and negative user evaluations; CSR messages having a comparable number of positive and negative user evaluations lead to a higher identification with the company than CSR messages having no user evaluations; and CSR messages having no user evaluations lead to a higher identification with the company than CSR messages having mostly negative user evaluations.

Impact of Message Credibility and Identification on Corporate Reputation

Credibility is an important antecedent of corporate reputation (Fombrun, 1996). Previous research has shown that the credibility of advertising messages has a positive influence on the attitude towards the advertisements as well as the brand (Choi and Rifon 2002; MacKenzie and Lutz 1989). This is due to the consumer's judgment of advertisements and brands based on whether the message is deemed to be trustworthy. MacKenzie and Lutz (1989) argued that credibility can act as a peripheral cue, which causes higher persuasion even when the recipient does not actively process the message content. We therefore hypothesize that the credibility of corporate communication messages positively influences the attitude towards the company.

Hypothesis 3a: Message credibility increases corporate reputation.

Stakeholders' feelings of identification are likely to affect corporate reputation. Researchers on brand management have argued that a high degree of consumer identification with a brand reinforces brand equity (Kotler and Keller 2008; Muniz and O’Guinn 2001). Similarly, Sen and Bhattacharya (2001) argued that feelings of identification lead to more commitment toward the organization, which strengthens existing positive attitudes toward the company. Thus, we propose:

Hypothesis 3b: Identification with the company increases corporate reputation. 
Impact of Message Credibility and Identification on Word-of-Mouth

In interactive channels, comments and reviews are not simply existent but stakeholders can continuously respond to them with new comments and reviews. Positive word-of-mouth is largely created by stakeholders who feel involved with the organization or community. HennigThurau and Walsh (2003) indicated that people engage in positive word-of-mouth because it causes feelings of community membership. Likewise, Wang and Fesenmaier (2001) identified involvement as the main motivational factor of online community participation. The degree to which a person feels inclined to engage in positive word-of-mouth, consequently, is also determined by the degree of embeddedness, which includes feelings of closeness and inclusiveness. In addition, the credibility of the company's message is also likely to positively affect positive word-of-mouth intentions. When information about a company is perceived as more credible, stakeholders are more likely to have a favorable attitude toward the company, and hence are more likely to pass on the information to others and to recommend the company to others. We thus propose the following hypotheses:

Hypothesis 4a: Message credibility increases word-of-mouth intentions.

Hypothesis 4b: Identification with a company increases word-of-mouth intentions.

\section{Methodology}

We used an experimental approach to test our hypotheses. We created a fictitious company named HappyBev to mimic a real company, to avoid any interference from existing attitudes and associations regarding existing companies. The company website, shown in Appendix A, focuses on the company's efforts to manage its water sources in a responsible manner. We varied the interactive nature of the website as well as the valence of the user evaluations (if any), creating 
five conditions shown in Table 1. Subjects were randomly assigned to the conditions.

\section{INSERT TABLE 1 HERE}

\section{Research design and participants}

We developed a logo and a website for the company HappyBev. The website presents a brief history of the firm, an introduction to its product, bottled water called Aqua Montoé, and a description of its water management practices. We adapted an introduction text from Nestlé Waters' website (http://www.nestle-waters.com/environment/water-care/local-sustainable-watermanagement.html). It claims that the company treats its water sources in a sustainable and environmentally friendly way.

Interactivity is manipulated by creating two versions of HappyBev's website, one with a low and one with a high degree of interactivity. Similar to Thorson and Rodger's (2006) study, the first version displays only HappyBev's corporate message without any possibility to interact with the website, whereas the second version gives the visitor the possibility to comment on the corporate message. The second version of the website is divided into four different groups in order to manipulate the presence and valence of user evaluations. In addition to the two versions described above, conditions three, four and five each display ten existing comments, while conditions one and two do not show any comments.

According to Doh and Hwang (2009) who analyzed the impact of online product reviews, a ratio of eight positive to two negative reviews yields the highest credibility. Therefore, we adopted a ratio of 8:2 in condition three. In contrast, condition four has a ratio of 5:5, while condition five has a ratio of 2:8 of positive to negative comments. The comments were gathered from similar water management blogs and YouTube, and were adapted to match with 
HappyBev’s story.

A total of 339 undergraduate and graduate students from two major European universities (in two different countries) participated in the study. However, not all of them actually completed the questionnaire, resulting in a final sample of 205 respondents, of which 99 are female. ${ }^{1}$ Following Cohen's (1988) guidelines for sample size based on power analysis, such a sample should be sufficiently large to test the significance of medium-sized effects using five groups (with a significance level of 5\%). The majority of the drop-out occurred before respondents actually started filling in the questionnaire. Overall, the percentage of people who actually completed the questionnaire after they started filling it out was $84.43 \%$. However, the percentage of people starting the questionnaire after they viewed it was substantially lower, at $72.40 \%$. This pattern (which was similar across the five conditions) might suggest that the main reason for dropping out was a lack of interest in the topics discussed in the questionnaire sustainability/water management and online communication - rather than issues regarding the length of the questionnaire or the formulation of the questions.

On average, participants claim to be very familiar with the internet (6.62 on a 7-point Likert scale), and like using social media a lot (6.06 on a 7-point Likert scale). Almost all (97\%) respondents have a profile on a social networking site, whereas only $73 \%$ use social media to retrieve information about companies or products. ${ }^{2}$

\section{Procedure}

The respondents were asked to read the information on HappyBev's water management practices as well as the user evaluations provided below the story (if any). Depending on the condition, the respondents also either did or did not have the opportunity to post their own message. The respondents were led to believe that their message would be published within the next 24 hours 
on the main webpage. ${ }^{3} \mathrm{Next}$, respondents were asked to indicate their opinion regarding message credibility, their identification with the company, the company's reputation, whether they would engage in word-of-mouth, and the interactivity of the company's communication.

\section{Measurement Development}

All constructs were measured on 7-point Likert scales anchored by "strongly disagree” and "strongly agree”.

Message credibility was measured by using Newell and Goldsmith’s (2001) corporate credibility scale. This scale consists of two dimensions, trustworthiness and expertise, each comprising four individual items. For the purpose of this study, we were only interested in the trustworthiness scale. We used the connection and self-categorization scale developed by Einwiller et al. (2006) to measure identification and items from the Reputation Quotient scale (Fombrun et al. 2000) to measure the company's reputation. Because we focused on CSR, we used those items from the scale that address this dimension and adapted them based on the story. We developed two additional questions and adapted Maxham's scale (2001) to measure word-ofmouth intentions. Furthermore, we measured the perceived interactivity of the web page through a single 7-point semantic differential scale: “The interactivity of HappyBev’s website is: not interactive at all/very interactive”. All measurements are shown in the Appendix B.

\section{Manipulation Checks}

To test the success of the manipulations of the interactivity of the website and the valence of the user evaluations, we conducted a separate study among 64 undergraduate students. We separated this test from the main study because including the manipulation check in the main study can lead to biased results (Perdue \& Summers 1986). The respondents were randomly assigned to the five conditions in our study. In this study, we measured the perceptions of the interactivity of 
HappyBev's website using the scale developed by Liu (2003). This scale measures three dimensions of the interactivity of a website (active control, two-way communication, and synchronicity), of which only two-way communication was relevant for our study. We also measured the perceived valence of the evaluations through a single item consisting of five statements ranging from "There are substantially more positive comments than negative comments" to "There are substantially more negative comments than positive comments". Respondents were asked to select one of these statements, which were then coded from 1 to 5 . Perceived interactivity of HappyBev's website showed adequate reliability (Cronbach's alpha = .80). An analysis of variance showed that the five conditions differ significantly and substantially from each other in terms of perceived interactivity $\left(\mathrm{F}_{4,59}=7.66, \mathrm{p}<.01\right.$, partial eta squared $=$ .34). Particularly, post-hoc tests showed that Condition 1 (the non-interactive version) was perceived as significantly less interactive than the other four conditions (the interactive ones, with mean differences of $1.13,2.15,1.47$, and 1.70 for versions $2,3,4$, and 5 , respectively, all pvalues $<.05$ ). In addition, Condition 2 (the interactive version without any listed user evaluations) was perceived as significantly less interactive than Condition 3 (the interactive version with mainly positive user evaluations, mean difference $1.02, \mathrm{p}<.01$ ), but not significantly different from the other conditions.

A second analysis of variance showed significant differences between Conditions 3, 4 and 5 in terms of the perceived valence of the user evaluations $\left(F_{2,36}=6.43, \mathrm{p}<.01\right)$. However, posthoc tests showed significant differences between Conditions 3 (mostly positive, mean 1.33) and 4 (neutral, mean 2.58), and between Conditions 3 and 5 (mostly negative, mean 2.83), but not between Conditions 4 and 5 . The pattern of the means suggests that all versions were perceived as predominantly positive. 


\section{Analysis and Results}

We tested our model through structural equation modeling using partial least squares (through SmartPLS 2.0; Ringle et al. 2005). Our hypotheses imply a comparison of Condition 2 (interactive communication without any actual evaluations) to the other conditions. Particularly, Hypotheses 1a and 1b, concerning the impact of the interactivity of the corporate message (interactive versus non-interactive) imply a comparison between Conditions 1 and 2. Hypotheses 2 and 3, regarding the effect of the valence of evaluations provided on the web page, imply a comparison between Conditions 2 through 5. The significance of the coefficients was determined by estimating their standard errors through bootstrapping with 1,000 resamples.

\section{Measurement Validation}

To examine the convergent validity of the measurement model, we looked at the loadings of all indicators as well as the Average Variance Extracted (AVE) of each construct. These coefficients, displayed in Table 2, show that all items had sufficient loadings on the factors they belong to, and all factors had a sufficient composite reliability. In addition, the AVE values for each construct were above the recommended level of .50, indicating that the latent constructs explain at least $50 \%$ of the variance in their items.

\section{INSERT TABLE 2 HERE}

To assess the discriminant validity of our measures, we compared the square root of the AVE of each construct with the correlations of that construct with the other constructs in our model. As Table 3 shows, the square root of the AVE (shown on the diagonals of the correlation matrices) of each construct is larger than the largest correlation with another construct, 
suggesting sufficient discriminant validity. Finally, to assess measurement reliability, we examined the composite reliability coefficients. All coefficients are above .80 , indicating sufficient reliability (see Table 2).

INSERT TABLE 3 HERE

\section{Descriptive Statistics}

The means and standard deviations of the constructs in our model are displayed in Table 4. These are based on the unstandardized construct scores as calculated through PLS. The largest differences among the conditions are those between the two conditions with negative evaluations (Conditions 3 and 5) and the other conditions, mainly on the dimensions Message Credibility and Corporate Reputation.

INSERT TABLE 4 HERE

Results

The results of our analyses are shown in Figure 2. Hypotheses 1a and 1b stated that interactive CSR messages are more credible, and lead to a higher identification, than noninteractive CSR messages. Contrary to these hypotheses, the structural equation model through PLS showed no significant effects of the dummy variable representing Condition 2, indicating no significant difference between Conditions 1 and 2 in terms of the dependent variables message credibility $(\mathrm{b}=-.03, \mathrm{p}>.05)$ and identification $(\mathrm{b}=-.02, \mathrm{p}>.05) .{ }^{4}$ Because previous research has suggested that the perceived interactivity of a website might be more important than its actual interactivity (Thorson and Rodgers, 2006), we conducted an additional analysis including the effects of perceived interactivity. More specifically, we modeled perceived interactivity 
(rather than manipulated interactivity) as antecedent of message credibility and identification, and manipulated interactivity as antecedent of perceived interactivity. The results of this analysis, displayed in Figure 3, show that perceived interactivity is significantly and positively related to both message credibility $(\mathrm{b}=.28, \mathrm{p}<.01)$ and identification $(\mathrm{b}=.41, \mathrm{p}<.01)$ There is also a significant positive direct effect of perceived interactivity on word-of-mouth $(b=.14, \mathrm{p}<$ .05), suggesting that message credibility and identification only partially mediate the effect of interactivity. However, in contrast to the separate study we conducted to test our manipulations, actual (manipulated) interactivity does not significantly affect perceived interactivity (b = -.10, p $>$.05). This might be partly due to the fact that in the main study, we used a different measure for perceived interactivity.

INSERT FIGURE 2 HERE

INSERT FIGURE 3 HERE

Hypotheses 2a and 2b proposed the following rank order in terms of message credibility and identification, from high to low: messages with mostly positive user evaluations; messages with a comparable number of positive and negative user evaluations; messages with no user evaluations; and messages with mostly negative user evaluations. The results of the PLS model show that the valence of user evaluations significantly affects the credibility of the message as well as identification. Particularly, having mostly negative user evaluations (compared to no evaluations) significantly lowers both message credibility ( $b=-.30, \mathrm{p}<.01$ ) and identification (b $=-.25, \mathrm{p}<.01)$. On the other hand, having comparable numbers of negative and positive evaluations (compared to no evaluations) also significantly lowers message credibility (b = -..19, 
$\mathrm{p}<.05$ ), but not identification ( $\mathrm{b}=-.11, \mathrm{p}>.05$ ). Surprisingly, having mostly positive evaluations does not significantly affect message credibility $(b=-.06, p>.05)$ or identification $(b=-.06, p>.05)$ compared to having no evaluations. These results imply that while the existence of largely positive evaluations has a positive effect on message credibility, as soon as the number of negative evaluations reaches a certain point, message credibility decreases significantly. Therefore, Hypotheses $2 \mathrm{a}$ and $2 \mathrm{~b}$ are only partly confirmed. There are no significant direct effects of the valence of evaluations on corporate reputation and word-ofmouth intentions.

Hypotheses 3a-3b and 4a-4b state that message credibility and identification increase corporate reputation and word-of-mouth intentions. The results of the PLS model show that message credibility and identification are both significantly related to corporate reputation (message credibility: $\mathrm{b}=.55, \mathrm{p}<.01$; identification: $\mathrm{b}=.21, \mathrm{p}<.01$ ) and word-of-mouth intentions (message credibility: $\mathrm{b}=.26, \mathrm{p}<.01$; identification: $\mathrm{b}=.49, \mathrm{p}<.01$ ), confirming Hypotheses $4 \mathrm{a}$ and $4 \mathrm{~b}$, as well as $5 \mathrm{a}$ and $5 \mathrm{~b}$. Table 5 provides an overview of the results with respect to our hypotheses.

\section{INSERT TABLE 5 HERE}

\section{Discussion and Conclusions}

\section{Discussion of Findings}

This paper examines the impact of interactive corporate communication messages related to CSR on corporate reputation and word-of-mouth behavior. We discuss three main findings. First, our results suggest that although there seems to be little effect of allowing stakeholders to respond to a company's CSR messages, message credibility and stakeholder feelings of 
identification with the company increase when CSR messages are perceived as more interactive. This is consistent with findings of previous research (Thorson and Rodgers, 2006) that the perceived interactivity of a website influences people's attitude toward the person or organization to which the website belongs. On the one hand, interactivity gives stakeholders the possibility to respond to a company's claim, which makes the company reluctant to publish less credible claims, because they would be quickly denounced. On the other hand, interactivity establishes a bridge between stakeholders and the company, evoking feelings of identification towards the company. This finding is also consistent with Du et al.'s (2010) claim that the use of interactive online media enhances the effectiveness of CSR communication.

Second, our results show that CSR messages evoking mostly positive evaluations do not increase message credibility or stakeholder feelings of identification with the company. However, CSR messages evoking mixed or mostly negative evaluations decrease message credibility as well as identification. One explanation for these findings could be that participants may read more comments when they are negative, thereby giving greater weight to negative information. Although positive evaluations increase message credibility, people might be less interested in reading them. As a result, positive evaluations are more likely to be skipped, thus exerting nearly no influence on stakeholder attitude. Moreover, readers may assign more weight to negative information. This is because negative or extreme cues tend to be more informative than positive or moderate ones (Skowronski and Carlston 1989; Baumeister et al. 2001; Rozin and Royzman 2001).

Third, our findings suggest that message credibility positively impacts the reputation of a company, consistent with earlier findings (Goldsmith and Lafferty 1999; Goldsmith et al. 2000; MacKenzie and Lutz 1989). Our results also suggest that feelings of identification with the 
company have a positive effect on corporate reputation. This is because customers feel connected to the firm (Bhattacharya and Sen 2003; Kotler and Keller 2008; Muniz and O’Guinn 2001). Moreover, the results suggest that stakeholders who identify with a company are also likely to engage in positive word-of-mouth behavior about the company, consistent with findings by Hennig-Thurau and Walsh (2003) and Wang and Fesenmaier (2001).

\section{Theoretical and Managerial Implications}

This paper contributes to the literature on CSR communication in the following ways. First, it theoretically proposed and empirically tested a model that explains how and why the use of interactive CSR messages positively impacts the reputation of a company and word-of-mouth intentions. Our findings provide additional empirical evidence to the prior literature that examines the effects of CSR communication through more traditional channels (see Du et al. 2010), as well as the existing literature on interactivity, which focuses mostly on product brands (e.g., Van Noort et al. 2012).

Second, the impact of existing comments on stakeholders, beyond improving awareness, is rather ambivalent (Basuroy et al. 2003; Berger et al. 2010; Duan et al. 2008; Liu 2006). This paper examined the impacts of both positive and negative interactive evaluations and whether having mixed negative and positive evaluations is superior to no evaluations at all. We found that messages having mostly positive user evaluations do not the increase credibility of corporate communication and stakeholder feelings of identification compared to having no user evaluations. Consistent with prior literature (e.g., Skowronksi \& Carlston 1989), our findings suggest that having mixed negative and positive evaluations is inferior to no evaluations at all. That is, having a comparable number of positive and negative user evaluations lead to lower message credibility and identification among stakeholders. This paper adds to the empirical 
findings on different effects of positive and negative word-of-mouth (Chevalier and Mayzlin 2006; Clemons et al. 2006).

This paper also contributes to management practice. Interactive online channels are gaining importance for branding experts. Our findings suggest that companies should pay attention to these new forms of communication because their reputation is or will be affected by them. The insights gained in this study can help decision makers rationalize the use of interactivity in corporate communication. The results of this paper reveal that the use of interactive corporate communication has the potential to lead to a higher message credibility and feelings of identification towards the company, at least when stakeholders actually perceive the communication as interactive. That is, stakeholders should have the feeling that the company is interested in their opinions (two-way communication) and empowering them (symmetrical communication). Companies can build on this by communicating about CSR with their stakeholders through channels that truly allow stakeholders to have a say. Such interactions are likely to strengthen corporate reputation, and stakeholders are more inclined to pass on the information to others and to recommend the company to others. On the other hand, any negative user evaluations seem to be detrimental to corporate reputation, potentially cancelling out the positive effects of perceived interactivity. That is, interactivity and the presence of critical comments seem to have opposing effects on reputation. Therefore, companies must make sure they communicate CSR in a convincing and effective way and avoid generating too many negative responses.

\section{Limitations and Future Research}

We discuss a few limitations of this study and examine avenues for future research. First, future research can develop more complex interactive experimental scenarios to examine the 
effects of interactivity. For example, in such designs customers may have the possibility to comment on existing posts, while in our study they could only comment on the company information. More generally, in terms of Grunig and Hunt’s (1984) framework of public relations, we only focused on the two-way (versus one-way) nature of corporate communication, leaving aside the symmetrical (versus asymmetrical) nature of communication, i.e., whether communication only influences stakeholder opinions and behaviors, or also the company's opinions and behavior. In fact, in our study respondents were led to believe (for practical reasons) that the company controlled all communication because comments were only to be published after 24 hours - potentially, such a context suggests asymmetrical communication. In future studies, it could be interesting to investigate the effects of corporate responses to stakeholder comments, either implying an intention to change corporate policies as a result of the comments (symmetrical) or merely defending the company’s existing policies (asymmetrical).

Second, we need to be careful to draw a general conclusion about the effects of actual versus perceived interactivity, because actual interactivity was not significantly related to perceived interactivity in the main study (whereas it was in the manipulation check study). It might be the case that the measure of perceived interactivity that we used in the main study was less reliable or less valid than the measure we used in the manipulation check study.

Third, a similar precaution can be made regarding our conclusions regarding the effects of negative versus positive evaluations, as this effect is probably partly caused by message content. The positive and negative comments that we used in our study do not discuss exactly the same topics. In addition, the specific context which we used for the study might also have had an influence. For example, people might have certain expectations of a water company that makes them pay more attention to negative evaluations than to positive ones. In this study, we did not 
take into account the influence of message content on reputation. Future research can analyze content and how it matters. More specifically, future studies can use data mining techniques to mine message contents and learn what exactly impacts corporate reputation, especially since negative evaluations can have an immense impact on company's business practices, as Nestlé's story shows. Doing so can shed more light on the impact of user evaluations as compared to the impact of interactivity as such.

Fourth, we argued based on theory and previous empirical research that message credibility and identification would influence corporate reputation, but our research design leaves open the possibility that the causality has the reverse direction (i.e., reputation impacting message credibility and identification).

Finally, although we examined word-of-mouth intentions, the actual impact of a CSR message on word-of-mouth might be quite different from what our study suggests. Our study might suffer from a demand artifact in the sense that respondents were explicitly asked to read the company's message, whereas in real life they could have chosen to ignore it. Therefore, it might still be the case, as Fieseler et al. (2010) suggested, that the actual impact of CSR messages in interactive online channels is fairly limited. 


\section{Appendix A: Experimental Materials}

\section{Welcome to HappyBev.com}

written by HappyBev on Apr 19 3:21PM

\section{About HappyBev}

HappyBev is a beverage company, which produces premium bottled drinking water. It was founded in 1935 by René Gandolfini, a Swiss entrepreneur of Italian origin. The company's headquarters are located in Geneva, Switzerland. HappyBev currently has about 350 employees who are located all around the world.

HappyBev's financial performance was solid throughout the past two decades and the company faces fair growth prospects. Nevertheless, HappyBev is proud to present you with its innovative water management practices.

\section{Our Beverage}
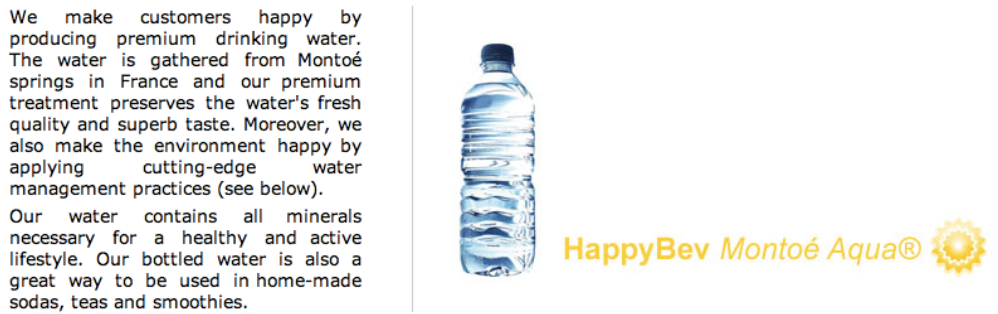

\section{Water Management}

Protecting groundwater sources is critical to the ecosystems and communities where we live and work. In a given geographical area, HappyBev seeks out and manages sources that can be used in a long-term, sustainable way.

\section{Hydrogeology expertise}

Therefore, we support legislation that protects groundwater for future generations. We always comply with local legislations and sometimes exceed them, applying our own internal standards, if they are considered to be insufficient.

We rely on a dedicated Water Resources Department, which provides advice and monitors water resources daily to ensure good stewardship. Our hydro-geologists implement protection measures on the recharge areas, and evaluate water flow volumes in cooperation with local authorities.

Our hydro-geologists also evaluate water quality and the investment that would be required to develop a new site (geological surveys, quality analysis, drilling). They review at least one year's worth of data on potential water sources and rely on historical variations in seasonal weather patterns to understand the situation and ensure adequate water flow.

\section{Integrated water management}

We are committed to respecting the interests of our neighbors and the communities where we do business. We also believe it is important to work with all the groups involved to obtain the best results possible in protecting water resources, watersheds and land.

As a company, we strive to meet on a regular basis with those concerned, including local community members, government officials and non-governmental organizations, to discuss the potential impacts of water use on the ecosystem. Our Montoé springs are an excellent example
(see photo on the right). They are located in the (see photo on the right). fields and forests. In the early 70's, more intensive farming practices led to concerns about imbalances in the local ecosystem.

In 1975, a team of researchers set out to determine how to maintain high agricultural vields while preseving the quality of the spring water. Tests were conducted, and the spring wientifilly based recommendations. Later, in 1992, the company established an agricultural advisory firm called HappyAgri. This initiative is now referenced as a unique, remarkable example

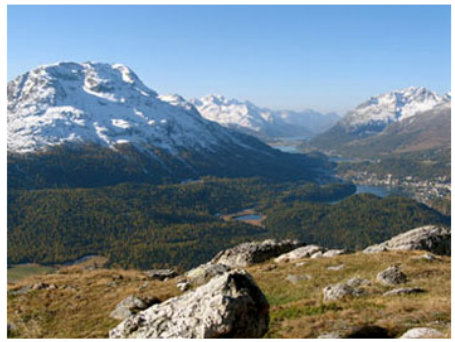


HappyBev Comment Posting Function

\begin{tabular}{|l|l|l|}
\hline Post Your Comment & \\
\hline & \\
\hline & \\
\hline & \\
\hline Submit & \\
\hline
\end{tabular}

HappyBev Comments (Examples)

Comments

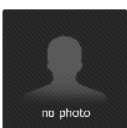

Dave Posted on May 13th 2010 9:23AM

«I choose to sow your money into small businesses such as HappyBev and not large corporations, that's the socially responsible thing to do. I am turned off by corporations and greedy CEOS.*

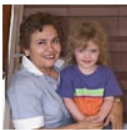

Maria Posted on May 11th 2010 5:48PM

«I am a Mexican irrigation engineer. I work as a teacher in a high school, and one of the subjects $I$ teach deals with use and conservation of water and soil. My on this page. Then, I'm going to translate it to my students. I hope I'll do pretty well. I hope you include more materials about conservation of natural resources. Thank you.»

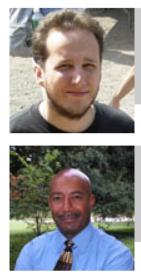

Mike Posted on May 6th 2010 1:05AM

«Water is a universal solution; water gives life to living things. Keep it up guys;

Howard Posted on May 2nd 2010 3:56PM

«You are doing a very good thing giving people the clean water that they need so

much. GOD bless you!

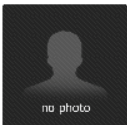

Jenn Posted on Apr 27th 2010 10:14AM

政

«I'm sure that HappyBev must bring whatever water it uses for its products to a

specific purity standard, but the realty is that whey then add substances, such as

as they, and everyone who drinks their products, continue to ignore the fact that they are detrimental to human health, they will continue to be detrimental to human health.* 


\section{Appendix B: Measurement of Constructs}

\begin{tabular}{|c|c|c|}
\hline Construct & Measurement & Source \\
\hline $\begin{array}{l}\text { Message } \\
\text { Credibility }\end{array}$ & $\begin{array}{l}\text { HappyBev makes truthful claims. } \\
\text { HappyBev is honest. } \\
\text { I trust HappyBev. } \\
\text { I do not believe what HappyBev tells me. }\end{array}$ & $\begin{array}{l}\text { Newell and } \\
\text { Goldsmith } \\
\text { (2001) }\end{array}$ \\
\hline Identification & $\begin{array}{l}\text { I have a sense of connection with HappyBev. } \\
\text { HappyBev are probably similar to me. } \\
\text { I consider myself as belonging to the group of people who are in } \\
\text { favor of HappyBev. } \\
\text { I feel associated with HappyBev. } \\
\text { Employees of HappyBev are probably similar to me. }\end{array}$ & $\begin{array}{l}\text { Einwiller et al. } \\
\text { (2006) }\end{array}$ \\
\hline $\begin{array}{l}\text { Corporate } \\
\text { Reputation }\end{array}$ & $\begin{array}{l}\text { HappyBev is an environmentally responsible company. } \\
\text { HappyBev has a responsible approach to water management. }\end{array}$ & $\begin{array}{l}\text { Fombrun et al. } \\
\text { (2000) }\end{array}$ \\
\hline Word-of-Mouth & $\begin{array}{l}\text { I will invite friends to learn more about HappyBev online. } \\
\text { I will recommend HappyBev to my friends. } \\
\text { I will talk about HappyBev on blogs and social networking sites. } \\
\text { I will talk positively about HappyBev. }\end{array}$ & $\begin{array}{l}\text { Maxham } \\
\text { (2001) }\end{array}$ \\
\hline $\begin{array}{l}\text { Perceived } \\
\text { Interactivity }\end{array}$ & $\begin{array}{l}\text { The interactivity of HappyBev's website is: not interactive at all - } \\
\text { very interactive }\end{array}$ & $\begin{array}{l}\text { Self- } \\
\text { developed }\end{array}$ \\
\hline $\begin{array}{l}\text { Perceived } \\
\text { Interactivity } \\
\text { (manipulation }\end{array}$ & $\begin{array}{l}\text { The website is effective in gathering visitors' feedback. } \\
\text { The website facilitates two-way communication between the } \\
\text { visitors and the site. } \\
\text { It is difficult to offer feedback to the website. }\end{array}$ & Liu (2003) \\
\hline
\end{tabular}




\begin{tabular}{|c|c|c|}
\hline check study) & $\begin{array}{l}\text { The website makes me feel it wants to listen to its visitors. } \\
\text { The website does not at all encourage visitors to talk back. } \\
\text { The website gives visitors the opportunity to talk back. }\end{array}$ & \\
\hline $\begin{array}{l}\text { Valence of User } \\
\text { Evaluations } \\
\text { (manipulation } \\
\text { check study) }\end{array}$ & $\begin{array}{l}\text { There are substantially more positive comments than negative } \\
\text { comments. } \\
\text { There are slightly more positive comments than negative comments. } \\
\text { There are about equal numbers of positive comments and negative } \\
\text { comments. } \\
\text { There are slightly more negative comments than positive comments. } \\
\text { There are substantially more negative comments than positive } \\
\text { comments. }\end{array}$ & $\begin{array}{l}\text { Self- } \\
\text { developed }\end{array}$ \\
\hline
\end{tabular}




\section{Endnotes}

${ }^{1}$ A chi-square test reveals no significant differences of gender distribution among the five groups $\left(\chi^{2}=3.01, \mathrm{df}=4, \mathrm{p}=.56\right)$, nor any significant differences in the distribution of the 117 western and 88 non-western respondents $\left(\chi^{2}=1.19, \mathrm{df}=4, \mathrm{p}=.88\right)$. However, differences were found in education level among the five groups $\left(\chi^{2}=15.78, \mathrm{df}=4, \mathrm{p}=.05\right)$. However, since five cells have an expected count less than five, the results might not be meaningful. Indeed, by excluding the respondents with only a high school diploma, the chi-square test shows no more disparities $\left(\chi^{2}=3.06, d f=4, p=.55\right)$. Nevertheless, we conducted further analyses both with and without these seven respondents to check whether there were significant differences between the two data sets. As no significant differences could be found, it is thus assumed that the distribution of education among the five groups is about equal. The mean age of all participants is 24.98 years. An ANOVA test shows that there are no significant differences in the mean age across the five groups $(\mathrm{F}=0.67, \mathrm{p}=.61)$.

${ }^{2}$ The means on all of these variables are also not significantly different across the five groups (for familiarity with the Internet, $\mathrm{F}_{4,199}=0.37, \mathrm{p}=.83$; for liking of social media, $\mathrm{F}_{4,196}=1.16, \mathrm{p}$ $=.33$; for use of networking sites, $\mathrm{F}_{4,200}=0.56, \mathrm{p}=.69$; and for using social media for information about companies, $\mathrm{F}_{4,199}=1.15, \mathrm{p}=.34$ ).

${ }^{3}$ The reason for this choice is that the online survey system did not allow for the respondent's own comment to be 'published' immediately.

${ }^{4}$ We also tested the significance of the differences between the non-interactive condition (Condition 1) and the interactive ones using dummy coding with Condition 1 as the references category. The results show that the condition with mostly negative comments (Condition 5) scores significantly lower than the non-interactive condition on all dimensions except word-of- 
mouth (see the significance levels provided in Table 4). In addition, the condition with balanced negative and positive comments scores significantly lower than the non-interactive condition on message credibility and reputation. 


\section{References}

Arvidsson, S. (2010). Communication of corporate social responsibility: A study of the views of management teams in large companies. Journal of Business Ethics, 96(3), 339-354.

Basuroy, S., Chatterjee, S., \& Ravid, S. (2003). How critical are critical reviews? The box office effects of film critics, star power, and budgets. Journal of Marketing, 67, 103-117.

Baumeister, R., Bratslavsky, E. Finkenauer, C., \& Vohs, K. (2001). Bad is stronger than good. Review of General Psychology, 5(4), 323-370.

Berger, J., Sorensen, A. \& Rasmussen, S. (2010). Positive effects of negative publicity: Can negative reviews increase sales? Marketing Science, 29(5), 815-827.

Bhattacharya, C.B. \& Sen, S. (2003). Consumer-company identification: A framework for understanding consumers relationships with companies. Journal of Marketing, 67(2), 7688.

Bickart, B. \&d Schindler, R. (2001). Internet forums as influential sources of consumer information. Journal of Interactive Marketing, 15(3), 31-40.

Chevalier, J. \& Mayzlin, D. (2006). The Effect of Word of Mouth on Sales: Online Book Reviews. Journal of Marketing Research, 43(3), 345-354.

Choi, S. and Rifon, N. (2002). Antecedents and consequences of web advertising credibility: A study of consumer response to banner ads. Journal of Interactive Advertising, 3(1), 1224.

Clemons, E., Gao, G. and Hitt, L. (2006). When online reviews meet hyperdifferentiation: A study of the craft beer industry. Journal of Management Information Systems, 23(2), 149171.

Cohen, J. (1988). Statistical power analysis for the behavioral sciences (2nd ed.). Hillsdale, NJ: 


\section{Lawrence Erlbaum.}

Doh, S. and Hwang, J. (2009). How consumers evaluate eWOM (electronic word-of-mouth) messages. CyberPsychology \& Behavior, 12(2), 193-197.

Du, S., Bhattacharya, C.B. and Sen, S. (2010). Maximizing business returns to corporate social responsibility: The role of corporate social responsibility communication. International Journal of Management Reviews, 12(1), 8-19

Duan, W., Gu, B. and Whinston, A. (2008). Do online reviews matter? An empirical investigation of panel data. Decision Support Systems, 45(4), 1007-1016.

East, R., Hammond, K. and Lomax, W. (2008). Measuring the impact of positive and negative word of mouth on brand purchase probability. International Journal of Research in Marketing, 25(3), 215-224.

Einwiller, S., Fedorikhin, A., Johnson, A. and Kamins, M. (2006). Enough is enough! When identification no longer prevents negative corporate associations. Journal of the Academy of Marketing Science , 34(2), 185-194.

European Commission. (2011). A renewed EU strategy 2011-14 for corporate social responsibility. (retrieved on February 20, 2013, from) http://eurlex.europa.eu/LexUriServ/LexUriServ.do?uri=COM:2011:0681:FIN:EN:PDF.

Fieseler, C., Fleck, M. and Meckel, M. (2010). Corporate social responsibility in the blogosphere. Journal of Business Ethics, 91, 599-614.

Fiore, A.M., Jin, H.-J. and Kim, J. (2005). For fun and profit: Hedonic value from image interactivity and responses toward an online store. Psychology and Marketing, 22(8), 669-94.

Folkes, V. S. and Kamins, M. A. (1999). Effects of information about firms' ethical and unethical 
actions on consumers' attitudes. Journal of Consumer Psychology, 8(3), 243-259.

Fombrun, C.J. (1996). Reputation: realizing value from the corporate image. Harvard Business School Press, Boston.

Fombrun, C.J., Gardberg, N. and Sever, J. (2000). The reputation quotient: A multi-stakeholder measure of corporate reputation. The Journal of Brand Management, 7(4), 241-255.

Forehand, M. R., \& Grier, S. (2003). When is honesty the best policy? the effect of stated company intent on consumer skepticism. Journal of Consumer Psychology, 13(3), 349356.

Goldsmith, R. and Lafferty, B. (1999). Corporate credibility's role in consumer's attitudes and purchase intentions when a high versus a low credibility endorser is used in the ad. Journal of Business Research, 44(2), 109-116.

Goldsmith, R., Lafferty, B. and Newell, S. (2000). The impact of corporate credibility and celebrity credibility on consumer reaction to advertisements and brands. Journal of Advertising, 29(3), 43-54.

Grunig, J. E., \& Hunt, T. (1984). Managing public relations: Holt, Rinehart and Winston, New York.

Hennig-Thurau, T. and Walsh, G. (2003). Electronic word of mouth: Motives for andconsequences of reading customer articulations on the Internet. International Journal of Electronic Commerce , 8(2), 51-74.

Kim, D., Nam, Y. and Kang, S. (2010). An analysis of corporate environmental responsibility on the global corporate Web sites and their dialogic principles. Public Relations Review, 36, 285-288.

Kotler, P. and Keller, K. (2008). Marketing Management. Prentice-Hall, Upper Saddle River. 
Liu, Y. (2003). Developing a scale to measure the interactivity of web sites. Journal of Advertising Research, 43(2), 207-216.

Liu, Y. (2006). Word of mouth for movies: Its dynamics and impact on box office revenue. Journal of Marketing, 70(3), 74-89.

Liu, Y., \& Shrum, L. (2002). What is interactivity and is it always such a good thing? implications of definition, person, and situation for the influence of interactivity on advertising effectiveness. Journal of Advertising, 31(4), 53-64.

MacKenzie, S. and Lutz, R. (1989). An empirical examination of the structural antecedents of attitude toward the ad in an advertising pretesting context. Journal of Marketing, 53(2), 48-65.

Macias, W. (2003). A beginning look at the effects of interactivity, product involvement and web experience on comprehension: Brand web sites as interactive advertising. Journal of Current Issues \& Research in Advertising, 25(2), 31-44.

Maxham, J. (2001). Service recovery's influence on consumer satisfaction, positive word-ofmouth, and purchase intentions. Journal of Business Research, 54(1), 11-24.

McCarthy, C. (2010). Nestle mess shows sticky side of Facebook pages. 19 March 2010. http://news.cnet.com/8301-13577_3-20000805-36.html. Accessed 9 July 2013.

McMillan, S. J. (2006). Exploring models of interactivity from multiple research traditions: Users, documents, and systems. Handbook of New Media: Social Shaping and Consequences of ICTs, 205-229.

McMillan, S. J., \& Hwang, J. (2002). Measures of perceived interactivity: An exploration of the role of direction of communication, user control, and time in shaping perceptions of interactivity. Journal of Advertising, 31(3), 29-42. 
Muniz, A. and O'Guinn, T. (2001). Brand community. Journal of Consumer Research, 27(4), 412-432.

Newell, S. and Goldsmith, R. (2001). The development of a scale to measure perceived corporate credibility. Journal of Business Research, 52(3), 235-247.

Perdue, B. C., \& Summers, J. O. (1986). Checking the success of manipulations in marketing experiments. Journal of Marketing Research, 23(November), 317-326.

Post, T. (2007). Newspapers struggle with online comments. Minnesota Public Radio NewsQ, October 25 (available at: http://minnesota.publicradio.org/display/web/2007/10/25/onlinecomments/).

Rafaeli, S., \& Sudweeks, F. (1997). Networked interactivity. Journal of Computer-Mediated Communication, 2(4).

Ringle, C.M., Wende, S., \& Will, A. (2005). SmartPLS 2.0 (beta). SmartPLS, Hamburg, Germany (available at: http://www.smartpls.de).

Rozin, P., \& Royzman, E. B. (2001). Negativity bias, negativity dominance, and contagion. Personality and Social Psychology Review, 5(4), 296-320.

Sen, S., Bhattacharya, C. B., \& Korschun, D. (2006). The role of corporate social responsibility in strengthening multiple stakeholder relationships: A field experiment. Journal of the Academy of Marketing Science, 34(2), 158-166.

Sen, S. and Lerman, D. (2007). Why are you telling me this? An examination into negative consumer reviews on the web. Journal of Interactive Marketing, 21(4), 76-94.

Simmons, C. J., \& Becker-Olsen, K. L. (2006). Achieving marketing objectives through social sponsorships. Journal of Marketing, 70(October), 154-169.

Skowronski, J. and Carlston, D. (1989). Negativity and extremity biases in impression formation: 
A review of explanations. Psychological Bulletin, 105(1), 131-142.

Smith, R. and Vogt, C. (1995). The effects of integrating advertising and negative word-ofmouth communications on message processing and response. Journal of Consumer Psychology, 4(2), 133-151.

The Economist (2010). The other oil spill. The Economist, June 24.

Thorson, K. and Rodgers, S. (2006). Relationships between blogs as eWOM and interactivity, perceived interactivity, and parasocial interaction. Journal of Interactive Advertising, $6(2), 34-44$.

Van Halderen, M. D., van Riel, C. B. and Brown, T. J. (2011). Balancing between legitimacy and distinctiveness in corporate messaging: A case study in the oil industry. Corporate Reputation Review, 14(4), 273-299.

Van Noort, G., Voorveld, H. A., \& van Reijmersdal, E. A. (2012). Interactivity in brand web sites: Cognitive, affective, and behavioral responses explained by consumers' online flow experience. Journal of Interactive Marketing, 26, 223-234.

Wang, Y. and Fesenmaier, D. (2001). Assessing motivation of contribution in online communities: An empirical investigation of an online travel community. Electronic Markets, 13(1), 33-45.

Walther, J. B., DeAndrea, D., Kim, J., \& Anthony, J. C. (2010). The influence of online comments on perceptions of antimarijuana public service announcements on YouTube. Human Communication Research, 36(4), 469-492

YouTube. (2010). Have a break? YouTube, March 17 (available at: http://www.youtube.com/watch?v=VaJjPRwExO8). 
Figure 1. Conceptual Model

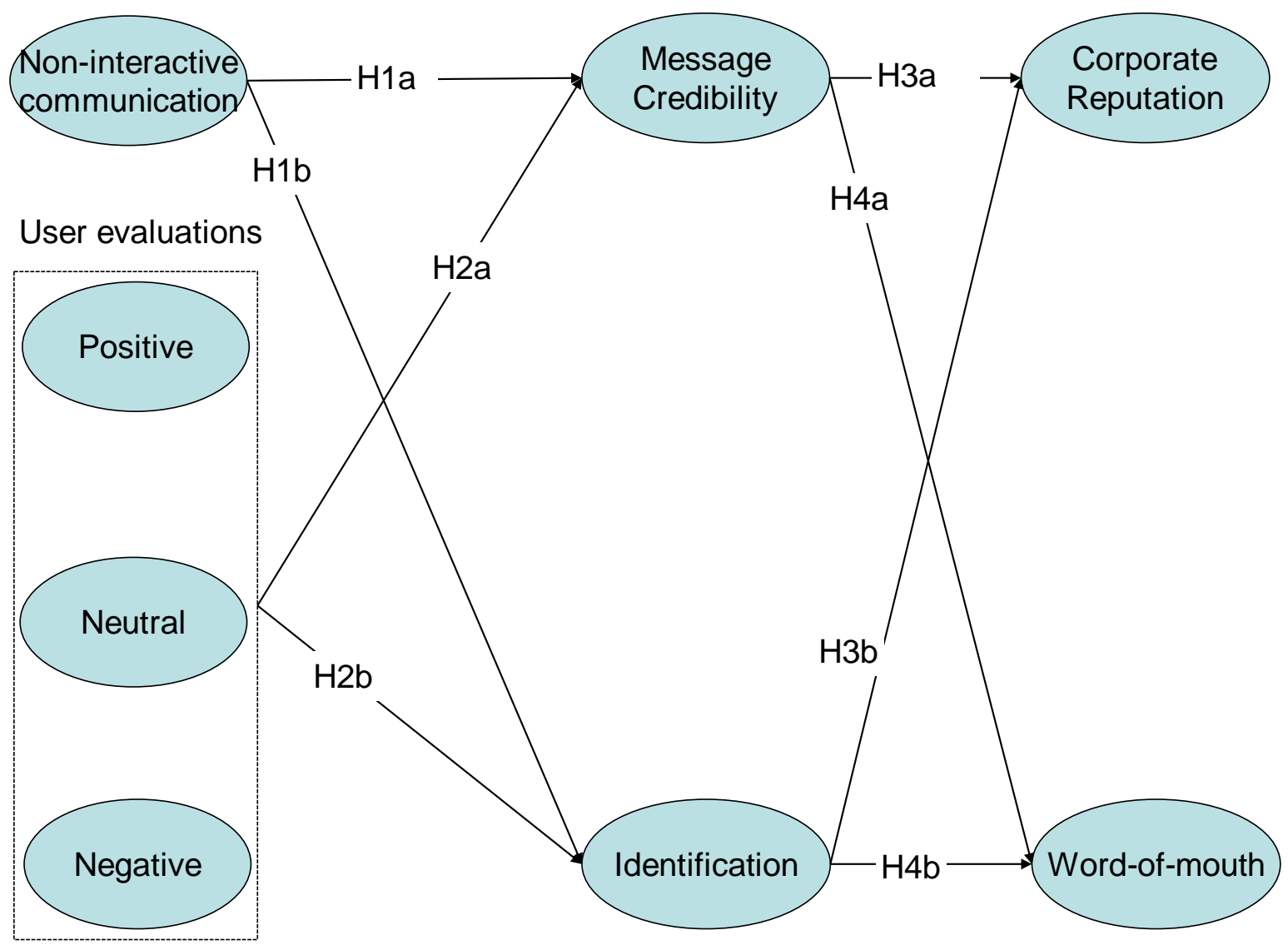


Figure 2. Results

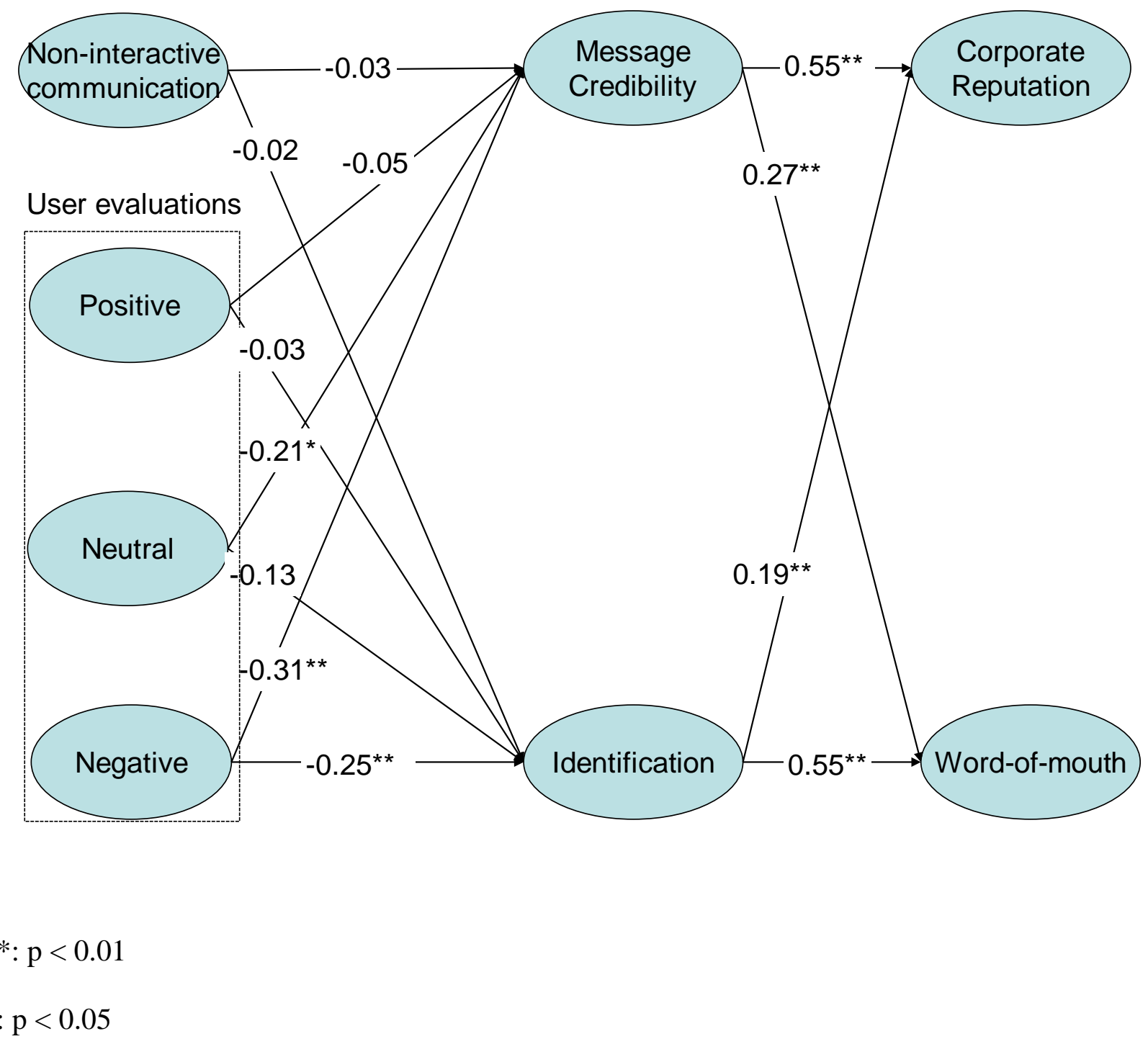


Figure 3. Results including perceived interactivity

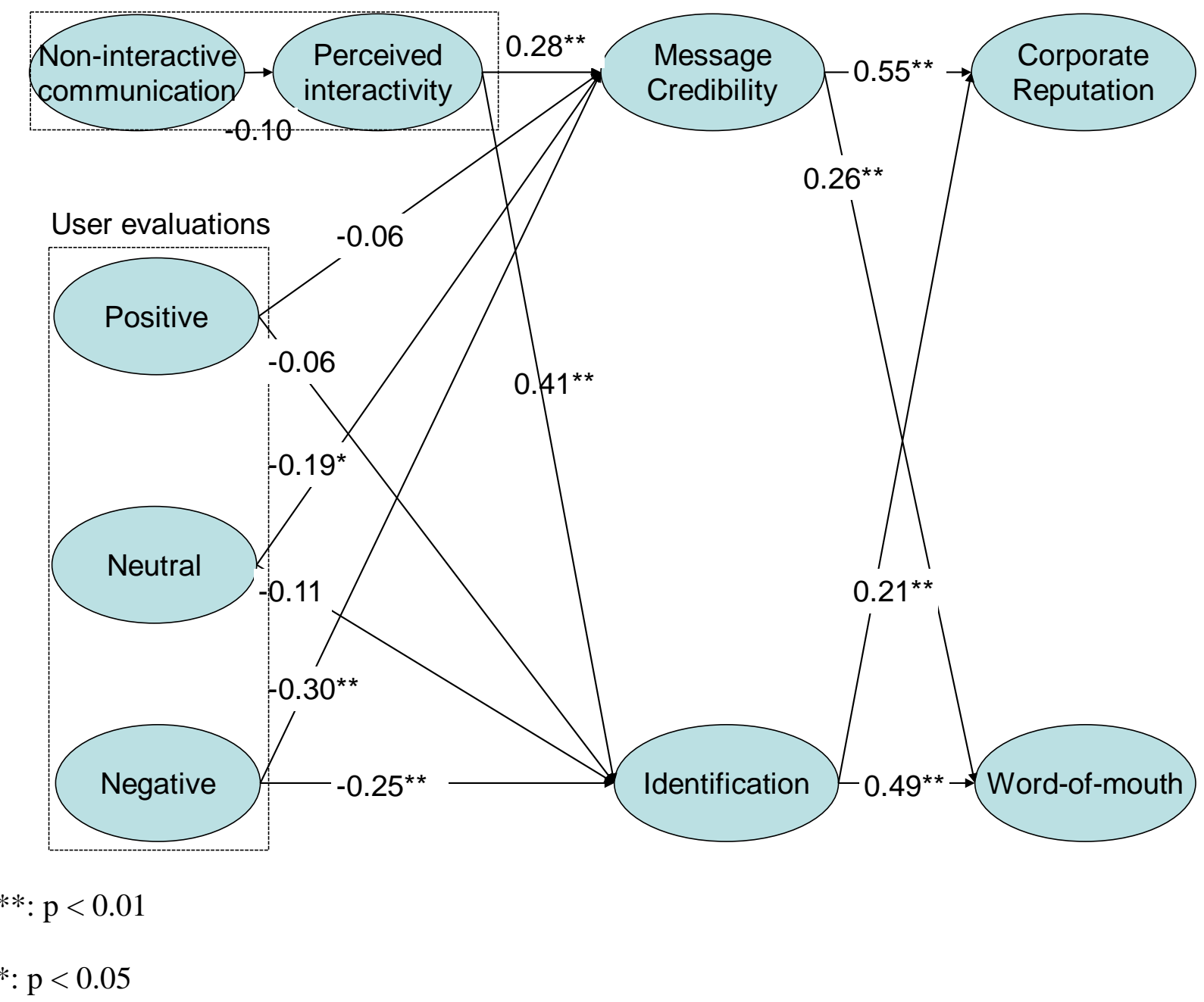


Table 1. Overview of Conditions

\begin{tabular}{|lcccc|}
\hline \multirow{2}{*}{ Interactivity } & \multicolumn{4}{c|}{ Positive : Negative Comments } \\
\cline { 2 - 5 } & $0: 0$ & $8: 2$ & $5: 5$ & $2: 8$ \\
\hline Non-Interactive & Condition 1 & - & - & - \\
\hline Interactive & Condition 2 & Condition 3 & Condition 4 & Scenario 5 \\
\hline
\end{tabular}


Table 2. Loading, Reliability, and AVE of Latent Variables

\begin{tabular}{|c|c|c|c|}
\hline & Item Loading & Composite Reliability & AVE \\
\hline Message Credibility & & .90 & .69 \\
\hline Truthful claims & 0.91 & & \\
\hline Honest & 0.91 & & \\
\hline Trust & 0.87 & & \\
\hline Do not believe & 0.59 & & \\
\hline Identification & & .95 & .78 \\
\hline Sense of connection & 0.93 & & \\
\hline Similar to me & 0.91 & & \\
\hline Belonging & 0.92 & & \\
\hline Feel associated & 0.90 & & \\
\hline Employees similar to me & 0.74 & & \\
\hline Corporate Reputation & & .97 & .94 \\
\hline Environmentally responsible & 0.97 & & \\
\hline Responsible water management & 0.97 & & \\
\hline Word-of-Mouth & & .91 & .67 \\
\hline Invite friends & 0.86 & & \\
\hline Recommend & 0.91 & & \\
\hline Talk on blogs & 0.84 & & \\
\hline Talk positively & 0.84 & & \\
\hline
\end{tabular}


Table 3. Construct Correlations

\begin{tabular}{|c|c|c|c|c|c|c|c|c|}
\hline Construct & (1) & (2) & (3) & (4) & (5) & (6) & (7) & (8) \\
\hline $\begin{array}{l}\text { (1) Non-Interactive } \\
\text { Communication }\end{array}$ & 1.00 & & & & & & & \\
\hline $\begin{array}{l}\text { (2) Positive User } \\
\text { Evaluations }\end{array}$ & -.25 & 1.00 & & & & & & \\
\hline $\begin{array}{l}\text { (3) Neutral User } \\
\text { Evaluations }\end{array}$ & -.25 & -.25 & 1.00 & & & & & \\
\hline $\begin{array}{l}\text { (4) Negative User } \\
\text { Evaluations }\end{array}$ & -.24 & -.25 & -.25 & 1.00 & & & & \\
\hline (5) Message Credibility & .11 & .09 & -.11 & -.24 & .83 & & & \\
\hline (6) Identification & .08 & .07 & -.05 & -.20 & .63 & .88 & & \\
\hline (7) Corporate Reputation & .10 & .11 & -.13 & -.24 & .71 & .57 & 0.94 & \\
\hline (8) Word-of-Mouth & -.01 & .07 & -.05 & -0.17 & .61 & 0.72 & 0.62 & 0.82 \\
\hline
\end{tabular}


Table 4. Descriptive Statistics

\begin{tabular}{|c|c|c|c|c|c|c|c|c|c|c|}
\hline \multirow{3}{*}{ Construct } & \multicolumn{2}{|c|}{ Non-interactive } & \multicolumn{8}{|c|}{ Positive : Negative Comments } \\
\hline & & & \multicolumn{2}{|c|}{ 0:00 } & \multicolumn{2}{|c|}{$8: 2$} & \multicolumn{2}{|c|}{$5: 5$} & \multicolumn{2}{|c|}{$2: 8$} \\
\hline & Mean & SD & Mean & SD & Mean & SD & Mean & SD & Mean & SD \\
\hline Message Credibility & 4.44 & 0.77 & 4.53 & 1.23 & 4.40 & 0.86 & $3.96 * a$ & 1.03 & $3.66^{*}$ & 1.33 \\
\hline Identification & 3.51 & 1.36 & 3.59 & 1.42 & 3.49 & 1.33 & 3.15 & 1.38 & $2.73 *$ & 1.31 \\
\hline $\begin{array}{l}\text { Corporate } \\
\text { Reputation }\end{array}$ & 5.18 & 1.20 & 5.37 & 1.31 & 5.22 & 1.39 & $4.53 *$ & 1.34 & $4.21^{*}$ & 1.63 \\
\hline Word-of-Mouth & 1.92 & 0.77 & 2.21 & 0.89 & 2.07 & 0.85 & 1.85 & 0.96 & 1.63 & 0.85 \\
\hline
\end{tabular}

${ }^{\text {a }}$ Means marked with an asterisk differ significantly from the Non-Interactive condition at the 5\% level. 
Table 5. Summary of Results

\begin{tabular}{|c|c|c|}
\hline & Hypothesis & Results \\
\hline H1a & $\begin{array}{l}\text { Interactive CSR messages have a higher credibility than non- } \\
\text { interactive CSR messages. }\end{array}$ & $\begin{array}{l}\text { Partially supported } \\
\text { (for perceived } \\
\text { interactivity) }\end{array}$ \\
\hline H1b & $\begin{array}{l}\text { Interactive CSR messages create higher identification with the } \\
\text { company than non-interactive CSR messages.. }\end{array}$ & $\begin{array}{l}\text { Partially supported } \\
\text { (for perceived } \\
\text { interactivity) }\end{array}$ \\
\hline $\mathrm{H} 2 \mathrm{a}$ & $\begin{array}{l}\text { CSR messages having mostly positive user evaluations have a } \\
\text { higher credibility than CSR messages having a comparable number } \\
\text { of positive and negative user evaluations; CSR messages having a } \\
\text { comparable number of positive and negative user evaluations have } \\
\text { a higher credibility than CSR messages having no user evaluations; } \\
\text { and CSR messages having no user evaluations have a higher } \\
\text { credibility than CSR messages having mostly negative user } \\
\text { evaluations. }\end{array}$ & $\begin{array}{l}\text { Partially supported } \\
\text { (for negative } \\
\text { comments) }\end{array}$ \\
\hline $\mathrm{H} 2 \mathrm{~b}$ & $\begin{array}{l}\text { CSR messages having mostly positive user evaluations lead to a } \\
\text { higher identification with the company than CSR messages having } \\
\text { a comparable number of positive and negative user evaluations; } \\
\text { CSR messages having a comparable number of positive and } \\
\text { negative user evaluations lead to a higher identification with the } \\
\text { company than CSR messages having no user evaluations; and CSR } \\
\text { messages having no user evaluations lead to a higher identification }\end{array}$ & $\begin{array}{l}\text { Partially supported } \\
\text { (for negative } \\
\text { comments) }\end{array}$ \\
\hline
\end{tabular}




\begin{tabular}{|lll|}
\hline \multicolumn{3}{|l|}{$\begin{array}{l}\text { with the company than CSR messages having mostly negative user } \\
\text { evaluations. }\end{array}$} \\
\hline H3a & Message credibility increases corporate reputation. & Supported \\
\hline H3b & Identification with the company increases corporate reputation. & Supported \\
\hline H4a & Message credibility increases word-of-mouth intentions. & Supported \\
\hline H4b & Identification with a company increases word-of-mouth intentions. & Supported \\
\hline
\end{tabular}

